\title{
A head-to-head comparison of EQ-5D-5 L and SF-6D in Chinese patients with low back pain
}

\author{
Ziping Ye ${ }^{1}$, Lihua Sun ${ }^{1 *}$ and Qi Wang ${ }^{2}$
}

\begin{abstract}
Background: The comparative performance of the 3-level EuroQol 5-dimension and Short Form 6-dimension (SF-6D) has been investigated in patients with low back pain (LBP). The aim of this study was to explore the performance including agreement, convergent validity as well as known-groups validity of the 5-level EuroQol 5-dimension (EQ-5D-5 L) and SF-6D in Chinese patients with LBP.

Methods: Individuals with LBP were recruited from a large tertiary hospital in China. All subjects were interviewed using a standardized questionnaire including the EQ-5D-5 L, 36-item Short Form Health Survey (SF-36), the Oswestry questionnaire and socio-demographic questions from June 2017 to October 2017. Agreement was evaluated by intra-class correlation coefficients (ICCS) and Bland-Altman plots. Spearman's rank correlation coefficients were applied to assess convergent validity. For known-groups validity, the Mann-Whitney $U$ test or Kruskal-Wallis $H$ test were used, effect size (ES) and relative efficiency (RE) were also reported. The efficiency of detecting clinically relevant differences was measured by receiver operating characteristic (ROC) curves between pre-specified groups based on Oswestry disability index (ODI), ES and RE statistics were also reported.
\end{abstract}

Results: Two hundred seventy-two LBP patients (age 38.1, 38\% female) took part in the study. Agreement between the EQ-5D-5 L and the SF-6D was good (ICC 0.661) but with systematic discrepancy in the Bland-Altman plots. In terms of convergent validity, most priori assumptions were more related to EQ-5D-5 L than SF-6D, but MCS derived from SF36 was more associated with SF-6D. EQ-5D-5 L demonstrated better performance for most groups except location and general health grouped by the general assessment of health item from SF-36. Furthermore, when we applied $\mathrm{ODI}$ as external indicator of health status, the area under the ROC curve for EQ-5D-5 L was larger than that for the SF-6D $(0.892,95 \% \mathrm{Cl} 0.853$ to 0.931 versus $0.822,95 \% \mathrm{Cl} 0.771$ to 0.873$)$, the effect size was 0.63 for EQ-5D-5 $L$ and 0.44 for SF-6D, and it was proved that EQ-5D-5 $L$ was $42 \%$ more efficient than SF-6D at detecting differences measured by ODI.

Conclusions: Both EQ-5D-5 L and SF-6D are valid measures for LBP patients. Even though these two measures had good agreement, they cannot be used interchangeably. The EQ-5D-5 L was superior to the SF-6D in Chinese low back pain patients in this research, with stronger correlation to ODI and better known-groups validity. Further study needs to evaluate other factors, such as responsiveness and reliability.

Keywords: EQ-5D-5 L, SF-6D, The Oswestry questionnaire, Low back pain

\footnotetext{
* Correspondence: sunlh@syphu.edu.cn

${ }^{1}$ College of Business Administration, Shenyang Pharmaceutical University,

Shenyang, China

Full list of author information is available at the end of the article
}

(c) The Author(s). 2019 Open Access This article is distributed under the terms of the Creative Commons Attribution 4.0 International License (http://creativecommons.org/licenses/by/4.0/), which permits unrestricted use, distribution, and reproduction in any medium, provided you give appropriate credit to the original author(s) and the source, provide a link to the Creative Commons license, and indicate if changes were made. The Creative Commons Public Domain Dedication waiver (http://creativecommons.org/publicdomain/zero/1.0/) applies to the data made available in this article, unless otherwise stated. 


\section{Background}

Low back pain (LBP) is a common condition that can cause severe activity impairment and physical limitations [1]. Among employees of China, the prevalence of LBP is around 42.7-72.0\%, which makes LBP the most common cause of physical disability $[2,3]$. As an incapacitating disease, LBP is related to significant reduction in health-related quality of life (HRQoL) [4]. Hence, a valid and reliable HRQoL measure is needed to evaluate interventions or programs for LBP, and inform resource allocation decisions.

In general, HRQoL can be assessed using either disease-specific or generic instruments. The generic instruments can be in turn subdivided into: preference-based and non-preference based. The main benefit of generic preference-based measures is their broad range of health dimensions, which makes the comparisons of various disease, interventions and health programs possible [5]. Besides, generic preference-based measures provide a general estimate of health outcomes and can capture survival data in the form of quality-adjusted life years (QALYs), which is largely used as clinical effectiveness indicator [6].

The EuroQol 5-dimension (EQ-5D) is the most frequently used preference-based instrument around world [7]. Due to the high ceiling effects of the three level of EQ-5D (EQ-5D-3 L), a new version of the EQ-5D (known as EQ-5D-5 L) was developed [8]. With increasing availability of national value sets, crosswalk algorithms for converting $3 \mathrm{~L}$ scores to $5 \mathrm{~L}$ scores and more evidence about better psychometric properties of EQ-5D-5 L, we could observed increased uptake of the EQ-5D-5 L. Since Luo and colleagues [9] developed the scoring algorithm for the EQ-5D-5L based on Chinese preference, the EQ-5D-5 L is becoming popular in clinical studies in China. The Short Form 6-dimension (SF-6D) is a utility measure from the 36-item Short Form Health Survey (SF-36) [10], which has been considered as one of the most widely used generic measures of HRQoL in clinical trials. A number of studies have explored the performance of EQ-5D and SF-6D in various patient sets, and the results showed that comparative validity and responsiveness differed depending on the target population [11-14].

The comparative performance of the EQ-5D and SF-6D has been investigated in patients with LBP $[15,16]$, and it was found that EQ-5D and SF-6D were not interchangeable with the SF-6D largely outperforming the former in terms of measurement characteristics. However, both studies applied the 3-level version of the EQ-5D (EQ-5D-3 L), which was found to possess poor discriminative ability [17] and ceiling effects [18]. Several studies found better psychometric properties for the EQ-5D-5 L compared with EQ-5D-3 L [19-22]. Therefore, it seems vital to compare the EQ-5D-5L with SF-6D in LBP patients. Hence, this study attempts to evaluate agreement, convergent validity as well as known-groups of EQ-5D-5 L and SF-6D in patients with LBP.

\section{Methods \\ Study design and patient recruitment}

After being approved by ethics committee, consecutive patients of this cross-sectional study were recruited at the General Hospital of Shenyang Military Area Command in Shenyang city of China from June 2017 to October 2017. The inclusion and exclusion criteria were as follows.

Inclusion criteria: Patients with LBP aged more than 18 , with or without the lower limb pain, not experiencing any other coexisting treatments for pain except routine painkilling, understanding and speaking Mandarin; Exclusion criteria: patients with coexisting infection, malignancy, severe spinal cord disease or inflammatory joint disease; patients with myocardial infarction, cerebrovascular events, chronic lung disease, kidney disease or severe mental illness; pregnant women.

Confidence intervals were used to estimate the sample mean using following equation [23]:

$$
\mathrm{n}=\frac{\sigma^{2}}{\left[\frac{\omega}{1.96}\right]^{2}}
$$

$\omega$ is the margin of error, $\sigma$ is the outcome variable standard deviation (assumed to be the same under the null and alternative hypotheses). We wish $\omega$ to be 0.03 for all measures, $\sigma=0.238$ for EQ-5D-5 L [24], $\sigma=0.152$ for SF-6D [15], $\sigma=0.2026$ for ODI [15], which gives an estimated sample size for the survey of $n=242$, 98 and 176 for EQ-5D-5 L, SF-6D and ODI respectively. Assuming an $80 \%$ response rate to the survey, we would like to interview 300 LBP patients.

The diagnosis of LBP was based on the imaging information, physical examination as well as patients' complaints of LBP. As all the questionnaires used in this survey were verified, no pilot or pre-testing survey was performed. After submitting formal consent, every patient was questioned by the same interviewer. The interviewer was trained to conduct the survey in the same manner. At outpatient clinics, individuals were interviewed in the waiting room after consultation; at inpatient clinics, the survey was implemented in the sickroom before operation. The questions of the survey were organized in the following order: socio-demographic queries, Oswestry disability questionnaire, questions regarding the EQ-5D-5 L and SF-36. The interviewer, procedure, and questionnaire were the same for all patients. 


\section{Instruments and measures \\ EQ-5D-5 I}

The EQ-5D-5 L contains two parts that assesses health status of respondents on the day of interview [8]. The first part is a descriptive system with five items (mobility, self-care, pain/discomfort, usual activities, and anxiety/ depression), every item has five different levels of severity. Theoretically, the EQ-5D-5 L can define 3125 different health states. In accordance with the Chinese scoring algorithm [9], the EQ-5D-5 L gives a score from -0.39 to 1 where 1 is the best possible health state. The other part of EQ-5D-5 L is a visual analogue scale (EQ-VAS), asking interviewees to mark their present health status on a $20 \mathrm{~cm}$ vertical scale from 0 to 100 . The simplified Chinese version of EQ-5D-5 L in our research is approved by the EuroQol Group.

\section{SF-36 based SF-6D}

The SF-6D is an utility measure which was derived from the SF-36 [10]. Health status here is defined in terms of 6 dimensions (physical functioning, role limitation, social functioning, pain, energy and mental health), with each dimension having four to six levels. There are potentially 18,000 different health states. A value set for general population in Hong Kong [25] was used to estimate utility index for the SF-6D in this study. Utility score of SF-6D can range from 0.315 to 1.00. As recommended by previously published research [26], SF-36v2 was used as questionnaire when the survey was conducted instead of applying SF-6D as an independent instrument. The official version of SF-36 in simplified Chinese was authorized by QualityMetric [27].

\section{Oswestry disability index}

The Oswestry Disability Index (ODI) $[28,29]$ is an instrument measuring degree of disability in people with LBP. This questionnaire contains 10 items, including intensity of pain, personal care, lifting, walking, sitting, standing, sleeping, sex life, social life, and traveling. Each item is followed by 6 different levels, with scores from 0 (the least disability) to 5 (the most severe disability). The sum of all item scores is needed to transform into a 0 to $100 \%$ index. Patients with scores between 0 and $20 \%$ have minimal disability, 21 to $40 \%$ moderate disability, 41 to $60 \%$ severe disability, 61 to $80 \%$ unable to walk which was always defined as crippled, and 81 to $100 \%$ [30] bedbound or overstating their symptoms. Previous studies found the item about "sex life" culturally inappropriate for Chinese citizens [31]. Hence, we applied only 9 items in the ODI. The Chinese version of the ODI was an official version from Mapi Research Trust.

\section{Statistical analysis}

\section{Patient characteristics and descriptive statistics}

Only patients who completed all questionnaires were included in this analysis, we did not perform further imputation for missing scores. Continuous variables were reported as means and standard deviations (SD), frequencies and proportions were used for categorical variables. Descriptive statistics (mean, SD, median, inter-quartile range, minimum and maximum) for the ODI, EQ-5D-5 L and SF-6D were computed. Floor and ceiling effects for EQ-5D-5 L and SF-6D were evaluated by calculating the proportion of sample in the worst and best possible health states. Statistical analysis was conducted using IBM SPSS version 23.0 [32].

\section{Agreement between the EQ-5D-5 L and SF-6D}

When we repeat measurements by each of two methods on the same subjects, agreement analysis is essential to see whether they agree sufficiently for one method to replace the other one [33]. Both EQ-5D-5 L and SF-6D are measures for health utility, even though the EQ-5D-5 L has a possible range of -0.39 to 1.00 , while the SF-6D has a range of 0.315 to 1.00 . Hence, it is necessary for us to know to what degree these two utility measures agree and if it is possible to use these two measures interchangeably in the context of LBP patients in China. Agreement was assessed by intra-class correlation coefficients (ICCs) and Bland-Altman plots. The ICCs were calculated with two-way random effects model using average measures and absolute agreement. The ICCs can range between 0 and 1 . An ICC $<0.4$ suggests poor agreement, 0.4-0.59 fair, 0.6-0.74 good, and 0.75-1 excellent agreement [34]. Bland-Altman plots were also performed to explore the agreement between these two measures. In this method, the differences between the scores of the two instruments were plotted against the average utility scores [35].

\section{Convergent validity}

Following previous research [12, 36-38], the size of the correlations was compared for the EQ-5D-5 L and SF-6D scores with the ODI, the EQ-VAS, SF-36 physical (PCS) and mental component summary (MCS). The association was evaluated by Spearman's rank correlation coefficient, considering $0.9-1.0$ as very highly correlated, $0.7-0.9$ as highly correlated, $0.5-0.7$ as moderately correlated, and $0.3-0.5$ as low correlated [39].

\section{Known-groups validity}

General known-group validity EQ-5D-5 L and SF-6D scores were compared across important groups. Therefore, we divided sample by demographic characteristics, duration of pain [40], outpatients and inpatients, the 
general assessment of health item from SF-36 and EQ-VAS. It was hypothesized that patients with lower utility scores included the elderly [41], females [41], patients with longer duration of disease [36] and lower education [42], patients from rural areas [43] and with lower income [44], even though U-shaped relationships between income and health status were reported in some studies [45].

Age was divided into two groups based on medians [36]. Education level was regrouped into three sub-levels, $<=$ junior school, high school as well as $>=$ college. Income data was divided into four categories: <1000yuan, 10013500 yuan, $3501-5000$ yuan and $>5000$ yuan. We categorized the EQ-VAS scores into four groups, with score $<65$ as bad health, $65-79$ as fair health, $80-89$ as good health, and $90-100$ as excellent health [46]. To investigate whether dichotomous variables had significant impact on utility scores, Mann-Whitney U-tests were implemented [47]. For polychromous variables, Kruskal-Wallis $\mathrm{H}$ tests were used. The effect size (ES) and relative efficiency (RE) statistics were also applied. The ES was calculated using the statistics from above-mentioned tests, which was recommended by a recent published review [48], indicating the percentage of variance in the dependent variable explained by the independent variable. The RE was based on the ratio of statistics from the Mann-Whitney $\mathrm{U}$ or Kruskal-Wallis $\mathrm{H}$ tests on the EQ-5D-5 L and the SF-6D. The statistic of the SF-6D was the reference. Thus, if the RE was higher than 1, the EQ-5D-5 L was believed to be more efficient for discriminating between known groups than SF-6D.

Efficiency of detecting clinically relevant differences measured by ODI The efficiency of the EQ-5D-5 L and SF-6D to distinguish clinical relevant change of individuals with LBP was measured using the ES, RE, and receiver operating characteristic (ROC) curves. The utility instrument that creates the largest area under the ROC curve is considered to be the most sensitive measure at detecting differences of external indicator. An area under the curve (AUC) of 1 denotes perfect sensitivity, whereas an area of 0.5 represents less efficient [49]. ODI was applied as external indicator, which classified individuals into five different groups. For more valid outcomes [50], ODI was also dichotomized using different cut-off points.

\section{Results}

Patient characteristics and descriptive statistics of ODI, EQ-5D-5 L and SF-6D utility scores

Two hundred seventy-two patients out of 300 (total number of patients who participated in the survey) were included in the research, thus we achieved 91\% response rate. 28 individuals were not included in this research for the following reasons: not completing the questionnaires $(N=17)$ or being too young/too old for the research $(N=11)$.

Demographic and clinical characteristics are presented in Table 1. The mean age of participants was 38.1 years and the proportion of female was $38 \% .69 \%$ of sample was from urban population. About $40 \%$ of the patients had education of college. Around $28 \%$ of patients had income of 1001-3500 Yuan. Most patients had suffered LBP for more than 12 weeks.

The distribution of scores for the ODI, EQ-5D-5 L and SF-6D is displayed in Figs. 1, 2 and 3. Moreover, descriptive statistics of the ODI, EQ-5D-5 L and SF-6D index are demonstrated in Table 2. The mean ODI was 33.1\% (SD 0.210) (median 28.9\%; IQR (17.8, 44.4\%)), with a distribution skewed towards full health. The mean EQ-5D-5 L score was 0.603 (SD 0.336) (median 0.702; IQR $(0.438,0.862)$ ). The distribution of EQ-5D-5 L was skewed towards full health as well, which was akin to ODI. The score range of EQ-5D-5 L was from - 0.39 to 1. The mean scores of SF-6D was 0.593 (SD 0.143) (median 0.567; IQR $(0.500,0.656))$ with a distribution more

Table 1 Patient characteristics $(N=272)$

\begin{tabular}{|c|c|}
\hline Characteristics & Values \\
\hline \multicolumn{2}{|l|}{ Age (years) } \\
\hline Mean \pm SD & $38.1 \pm 14$ \\
\hline Median (interquartile range) & $35(26-49)$ \\
\hline \multicolumn{2}{|l|}{ Gender, N(\%) } \\
\hline Male & $168(62 \%)$ \\
\hline Female & $104(38 \%)$ \\
\hline \multicolumn{2}{|l|}{ Education, N(\%) } \\
\hline$\leq$ Primary school & $26(10 \%)$ \\
\hline Secondary school & $68(25 \%)$ \\
\hline High school & $68(25 \%)$ \\
\hline$\geq$ College & $110(40 \%)$ \\
\hline \multicolumn{2}{|l|}{ Location, N(\%) } \\
\hline City & $188(69 \%)$ \\
\hline Villiage & $85(31 \%)$ \\
\hline \multicolumn{2}{|l|}{ Income (yuan), N(\%) } \\
\hline$\leq 1000$ & $58(21 \%)$ \\
\hline $1001-3500$ & $75(28 \%)$ \\
\hline $3501-5000$ & $65(24 \%)$ \\
\hline $5001-10,000$ & $61(22 \%)$ \\
\hline$>10,000$ & $13(5 \%)$ \\
\hline \multicolumn{2}{|l|}{ Duration of LBP, N(\%) } \\
\hline$<4$ weeks & $50(18 \%)$ \\
\hline 4-12 weeks & $43(16 \%)$ \\
\hline$>12$ weeks & $179(66 \%)$ \\
\hline
\end{tabular}

LBP Low back pain, SD Standard deviation 


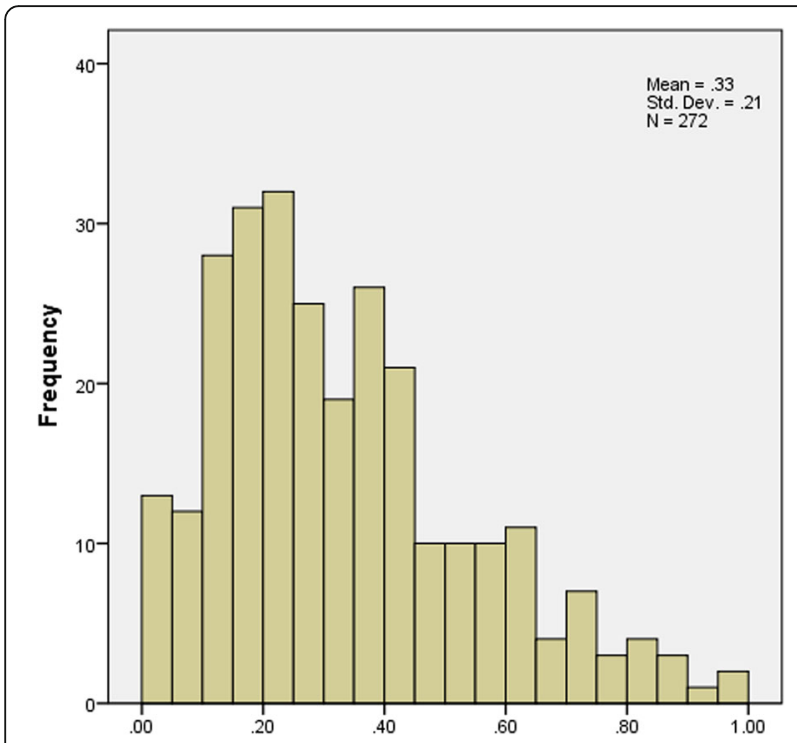

Fig. 1 The distribution of values for the ODI

symmetric around its mean. The score range of SF-6D was from 0.320 to 0.960 (Fig. 3).

Floor and ceiling effect were low for all three measurements. EQ-5D-5 L showed a slightly ceiling effect for $0.4 \%$ $(N=1)$, floor effect for $1.1 \%(N=3)$. The ODI and SF-6D yield no ceiling effect, but indicated a small floor effect for $1.1 \%(N=3)$ and $1.5 \%(N=4)$ of the respondents.

\section{Agreement between the EQ-5D-5 L and SF-6D}

The agreement between EQ-5D-5L and SF-6D was good, with ICC of 0.661 (95\%CI $0.57-0.733$ ). Considering the fact that ICC might be influenced by scaling

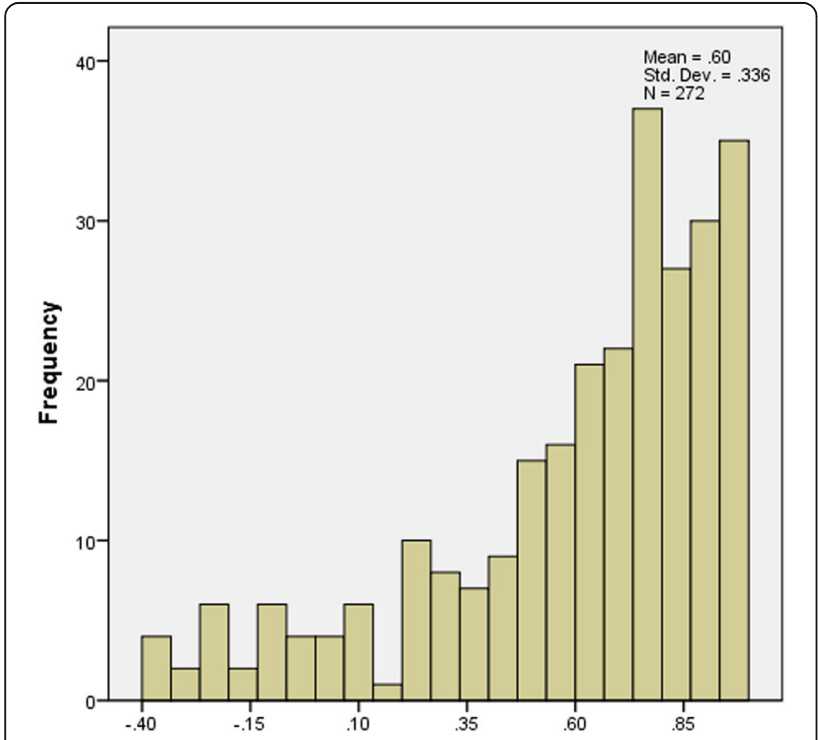

Fig. 2 The distribution of values for the EQ-5D-5 L

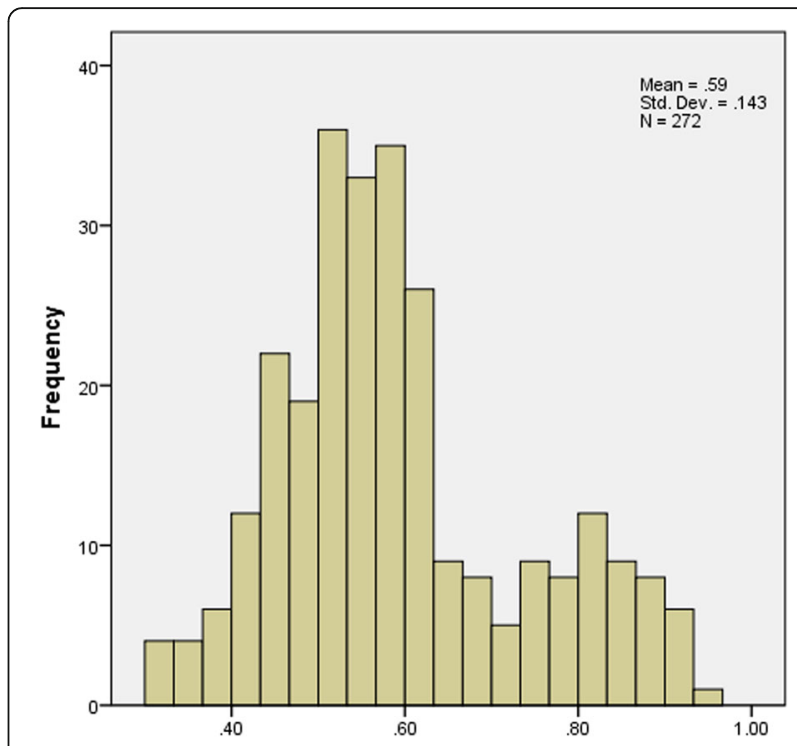

Fig. 3 The distribution of values for the SF-6D

differences between the EQ-5D-5L and the SF-6D, we reanalyzed the ICC after truncating the EQ-5D-5 L index score at 0 , results were similar with those without truncation. The Bland-Altman plot (Fig. 4) demonstrated a comparable picture with the ICC, as a mean difference in utility between these two measures of 0.01 . The plot showed that approximately $93.8 \%$ of the utility scores were between the bounds of agreement $(0.52$ and - 0.50) (Fig. 4). Particularly, EQ-5D-5 L and SF-6D utility index appeared to be less consistent at the relatively bad health status where sores were outside the limit of the agreement lie. Systematic discrepancy was observed in the mean difference between these two measures, with higher SF-6D scores at low mean utility scores, and higher EQ-5D-5 L scores at high mean utility scores.

Table 2 Descriptive statistics of ODI, EQ-5D and SF-6D utility scores, $n=272$

\begin{tabular}{llll}
\hline & ODI & EQ-5D-5 L & SF-6D \\
\hline Mean & $33.1 \%$ & 0.603 & 0.593 \\
Standard deviation & 0.210 & 0.336 & 0.143 \\
Median & $28.9 \%$ & 0.702 & 0.567 \\
Inter-quartile range & $(17.8,44.4 \%)$ & $(0.438,0.862)$ & $(0.500,0.656)$ \\
Maximum & $98 \%$ & 1.000 & 0.960 \\
Minimum & $0.0 \%$ & -0.390 & 0.320 \\
Floor effect, N(\%) & $3(1.1 \%)$ & $3(1.1 \%)$ & $4(1.5 \%)$ \\
Ceiling effect, N(\%) & $0(0 \%)$ & $1(0.4 \%)$ & $0(0 \%)$ \\
\hline
\end{tabular}

ODI Oswestry Disability Index, EQ-5D-5 L 5-level EuroQol 5-dimension, SF-6D Short Form 6-dimension 


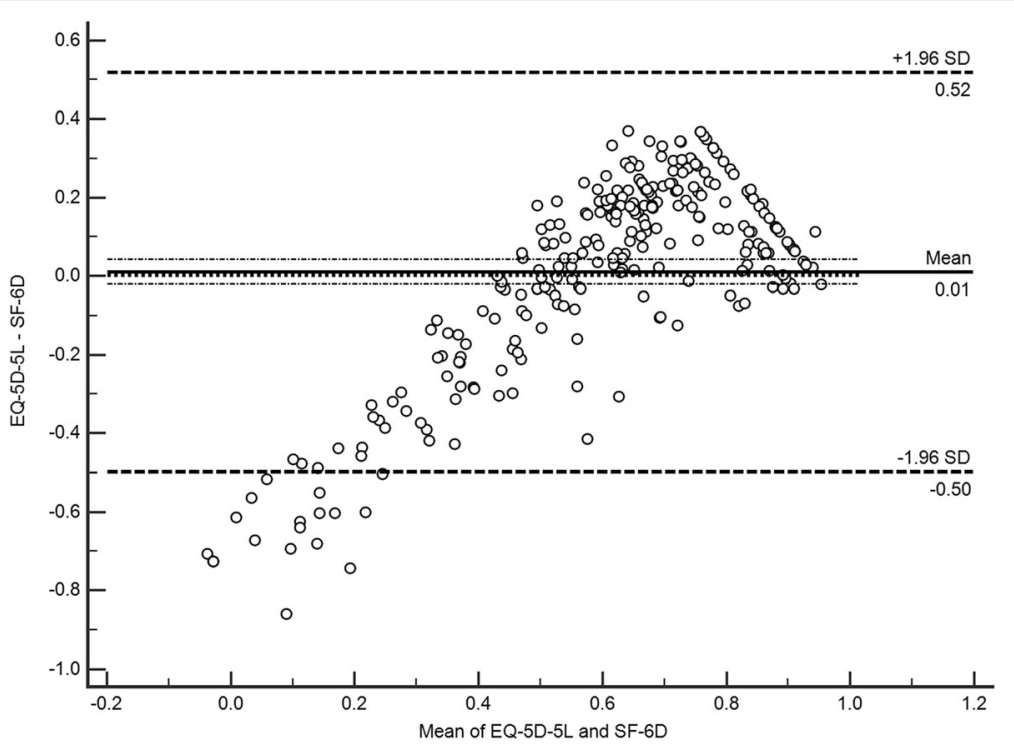

Fig. 4 Bland-Altman plot of difference in utility scores between the EQ-5D-5 L and SF-6D

\section{Convergent validity}

The spearman's rho correlation coefficients were based on various a priori assumptions. Our results suggested that EQ-5D-5 L was highly associated with ODI $(\rho=-0.828)$, and SF-6D was moderately correlated with ODI $(\rho=-$ $0.700)$. EQ-VAS was more interrelated with EQ-5D-5 L $(\rho=0.544)$ score than SF-6D $(\rho=0.472)$. In addition, PCS from SF-36 was highly correlated with both measures, but MCS showed week correlation with EQ-5D-5 L ( $\rho=0.403)$ but high correlation with SF-6D ( $\rho=0.709)$. All tests were proved to be statistically significant.

\section{Known-groups validity}

\section{General known-group validity}

General known-groups validity is displayed in Table 3. The EQ-5D-5 L and SF-6D were both able to detect significant utility differences between outpatients and inpatients, age, education as well as income. It was found that inpatients and the elderly had lower utility scores than outpatients and the young. Monotonic relationship was observed between education levels and utility scores measured by the EQ-5D-5 L. However, using SF-6D as utility measure, those who received high school education had similar utility scores compared to those who had higher education. Nevertheless, non-monotonic relationship was noticed between income levels and utility scores for both utility measures. The comparatively low utility scores of both EQ-5D-5 L and SF-6D were observed in the very good health group (SF-36) most probably because there was only one person in this sample. However, statistically significant difference of gender, location or duration of LBP was not detected by both measures. As for education, EQ-5D-5 L showed better known-groups validity $(P=0.005)$ than SF-6D $(P=0.014)$ with $\mathrm{RE}$ as 1.46. The RE values of the EQ-5D-5 L were greater than 1 at discriminating patient types, gender, age, education, duration of disease and general health grouped by EQ-VAS, indicating better known-groups validity of EQ-5D-5 L. However, the EQ-5D-5 L had RE less than 1 for location and general health grouped by the general assessment of health item from SF-36.

\section{Efficiency of detecting clinically relevant differences measured by ODI}

The EQ-5D-5L and SF-6D were both able to detect statistically significant utility differences depending on five categories of health states derived from the ODI (Table 4). The effect size was 0.63 for EQ-5D-5 L and 0.44 for SF-6D, and EQ-5D-5 L was found to have between 133 and $151 \%$ of the efficiency of the SF-6D at detecting differences measured by ODI. Additionally, the AUC score for EQ-5D-5 L was larger than that for the SF-6D $(0.892,95 \%$ CI 0.853 to 0.931 versus 0.822 , $95 \%$ CI 0.771 to 0.873 , Fig. 5). When the ODI was dichotomized into two categories by different cut-off point, the EQ-5D-5 L was proved to be between 133 to $148 \%$ efficient of the SF-6D (Table 5). For all dichotomous arrangements, the AUC scores revealed that both measures were sensitive to ODI. Moreover, the EQ-5D-5 L had higher AUC scores than SF-6D, indicating better sensitivity performance.

\section{Discussion}

The purpose of this research was to compare the performance of EQ-5D-5 L and SF-6D including agreement, convergent validity and known-groups validity in patients 
Table 3 Known-group validity of EQ-5D-5 $L$ and SF-6D

\begin{tabular}{|c|c|c|c|c|c|c|c|}
\hline \multirow[b]{2}{*}{ Patient characteristics } & \multicolumn{3}{|l|}{ EQ-5D-5 L } & \multicolumn{3}{|l|}{ SF-6D } & \multirow[b]{2}{*}{$\mathrm{RE}$} \\
\hline & Mean \pm SD & $P^{*}$ & ES & Mean \pm SD & $P^{*}$ & ES & \\
\hline \multicolumn{8}{|l|}{ Patient types } \\
\hline Outpatient & $0.75 \pm 0.21$ & 0.000 & 0.360 & $0.64 \pm 0.14$ & 0.000 & 0.230 & 1.57 \\
\hline Inpatient & $0.35 \pm 0.35$ & & & $0.51 \pm 0.1$ & & & \\
\hline \multicolumn{8}{|l|}{ Gender } \\
\hline Male & $0.62 \pm 0.33$ & 0.174 & 0.010 & $0.6 \pm 0.14$ & 0.279 & 0.004 & 1.57 \\
\hline Female & $0.57 \pm 0.34$ & & & $0.58 \pm 0.14$ & & & \\
\hline \multicolumn{8}{|l|}{ Age } \\
\hline Age $<=35$ & $0.71 \pm 0.24$ & 0.000 & 0.110 & $0.63 \pm 0.14$ & 0.000 & 0.070 & 1.45 \\
\hline Age $>35$ & $0.48 \pm 0.38$ & & & $0.55 \pm 0.14$ & & & \\
\hline \multicolumn{8}{|l|}{ Location } \\
\hline City & $0.6 \pm 0.35$ & 0.764 & 0.000 & $0.6 \pm 0.15$ & 0.584 & 0.001 & 0.30 \\
\hline Village & $0.61 \pm 0.31$ & & & $0.58 \pm 0.14$ & & & \\
\hline \multicolumn{8}{|l|}{ Education } \\
\hline$<=$ Junior school & $0.52 \pm 0.36$ & 0.02 & 0.040 & $0.56 \pm 0.13$ & 0.013 & 0.030 & 2.01 \\
\hline High school & $0.58 \pm 0.35$ & & & $0.61 \pm 0.15$ & & & \\
\hline$>=$ college & $0.68 \pm 0.28$ & & & $0.61 \pm 0.14$ & & & \\
\hline \multicolumn{8}{|l|}{ Income } \\
\hline$<1000 y u a n$ & $0.49 \pm 0.36$ & 0.000 & 0.1 & $0.54 \pm 0.13$ & 0.000 & 0.08 & 1.19 \\
\hline 1001-3500yuan & $0.51 \pm 0.37$ & & & $0.56 \pm 0.14$ & & & \\
\hline 3501-5000yuan & $0.74 \pm 0.24$ & & & $0.66 \pm 0.15$ & & & \\
\hline$>$ 5000yuan & $0.68 \pm 0.29$ & & & $0.61 \pm 0.12$ & & & \\
\hline \multicolumn{8}{|l|}{ Duration of disease } \\
\hline$<4$ Weeks & $0.63 \pm 0.36$ & 0.247 & 0.003 & $0.62 \pm 0.15$ & 0.333 & 0.001 & 1.27 \\
\hline 4-12 Weeks & $0.65 \pm 0.33$ & & & $0.60 \pm 0.14$ & & & \\
\hline$>12$ Weeks & $0.59 \pm 0.33$ & & & $0.58 \pm 0.14$ & & & \\
\hline \multicolumn{8}{|l|}{ Genaral health (EQ-VAS) } \\
\hline Bad & $0.44 \pm 0.37$ & 0.000 & 0.220 & $0.54 \pm 0.14$ & 0.000 & 0.170 & 1.29 \\
\hline Fair & $0.65 \pm 0.28$ & & & $0.59 \pm 0.11$ & & & \\
\hline Good & $0.79 \pm 0.19$ & & & $0.65 \pm 0.13$ & & & \\
\hline Excellent & $0.76 \pm 0.25$ & & & $0.68 \pm 0.14$ & & & \\
\hline \multicolumn{8}{|l|}{ General health (SF-36) } \\
\hline Very good & 0.49 & 0.000 & 0.230 & 0.56 & 0.000 & 0.250 & 0.91 \\
\hline Good & $0.77 \pm 0.25$ & & & $0.73 \pm 0.15$ & & & \\
\hline Fair & $0.74 \pm 0.29$ & & & $0.64 \pm 0.13$ & & & \\
\hline Bad & $0.63 \pm 0.27$ & & & $0.58 \pm 0.12$ & & & \\
\hline Very bad & $0.32 \pm 0.38$ & & & $0.49 \pm 0.1$ & & & \\
\hline
\end{tabular}

*P is from Mann-Whitney U-tests or Kruskal-Wallis $\mathrm{H}$ tests (2-tailed)

I only one person was in this group

EQ-5D-5 L 5-level EuroQol 5-dimension, SF-6D Short Form 6-dimension, SD Standard deviations, ES Effect size, RE Relative efficiency, EQ-VAS EuroQol visual analogue scale, SF-36 36-item Short Form Health Survey

with LBP. It was turned out that the agreement between EQ-5D-5 L and SF-6D was good. In terms of convergent validity, most priori assumptions were more associated with EQ-5D-5 L than SF-6D, but MCS derived from SF-36 was more correlated with SF-6D. As for known-groups validity, EQ-5D-5 L demonstrated better performance for most groups except location and the general assessment of health item from SF-36. Besides, EQ-5D-5 L had higher 
Table 4 Efficiency of EQ-5D-5 L and SF-6D to detect differences of five groups of ODI

\begin{tabular}{llll}
\hline & N (\%) & $\begin{array}{l}\text { EQ-5D-5 L } \\
\text { Mean } \pm \text { SD }\end{array}$ & $\begin{array}{l}\text { SF-6D } \\
\text { Mean } \pm \text { SD }\end{array}$ \\
\hline minimal disability & $95(35 \%)$ & $0.85 \pm 0.13$ & $0.7 \pm 0.14$ \\
moderate disability & $98(36 \%)$ & $0.67 \pm 0.18$ & $0.58 \pm 0.09$ \\
severe disability & $47(17 \%)$ & $0.4 \pm 0.24$ & $0.51 \pm 0.1$ \\
unable to walk & $24(9 \%)$ & $0.02 \pm 0.25$ & $0.44 \pm 0.07$ \\
bedbound & $8(3 \%)$ & $-0.23 \pm 0.14$ & $0.42 \pm 0.07$ \\
ES & & 0.63 & 0.44 \\
RE & & 1.42 & 1 \\
ROC curve $\quad$ AUC & & $0.892^{*}$ & $0.822^{*}$ \\
& & $(0.853,0.931)$ & $(0.771,873)$ \\
\hline
\end{tabular}

*indicates that area under the ROC curve statistically significantly greater than 0.5 and that measure has discriminatory power $(P<0.001)$

EQ-5D-5 L 5-level EuroQol 5-dimension, SF-6D Short Form 6-dimension, $O D I$ Oswestry Disability Index, SD Standard deviations, ES Effect size, RE Relative efficiency, ROC Receiver Operating Characteristic, AUC Area Under Curve, Cl Confidence Interval

ES, RE and AUC scores when we applied ODI as external indicator of health status, which indicated that EQ-5D-5 L was more efficient at detecting clinical differences.

We found that the distributions of ODI and EQ-5D-5 $\mathrm{L}$ skewed towards full health. However, the distribution of SF-6D was more symmetric around its mean, reflecting previous findings $[36,51]$. The distributions of these measures implied that EQ-5D-5 L might be more related to the ODI. Previously published papers declared that EQ-5D-5 L suffered high ceiling effect, which was not observed in this research [51]. One possible reason is that patients recruited in this research were from a tertiary hospital which patients visit only when they cannot

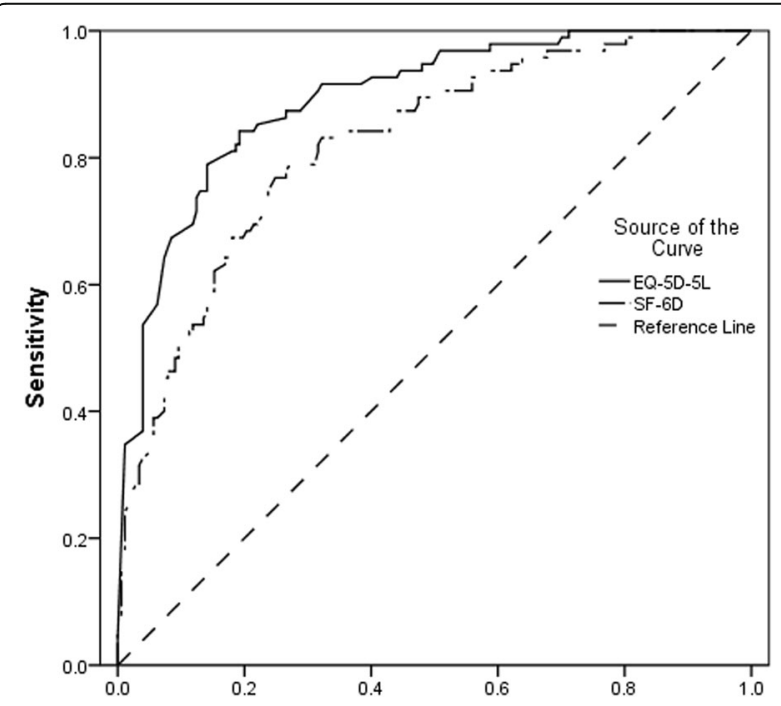

Fig. 5 Receiver operating characteristic (ROC) curves of EQ-5D-5 L and SF-6D endure their symptoms. In addition, unlike other diseases, LBP may drastically deteriorate quality of life [52].

The ICC of EQ-5D-5 L and SF-6D was 0.661, representing good agreement between these two measurements. This is higher than that in other similar studies in China, which is 0.448 for stable angina patients [53], 0.444 for chronic prostatitis patients [54]. Except for the fact that the study was conducted on a different disease, another possible reason for the discrepancy is that EQ-5D-3 L rather than EQ-5D-5 L were applied in these two studies. A smaller range of EQ-5D-5 L utility scores ( -0.39 to 1 ) was used compared with that of EQ-5D-3 L (-0.59 to 1$)$, which might account for the better agreement between the EQ-5D-5 L and SF-6D in this research. In consensus with previous studies in low back pain $[15,55,56]$, for poorer health status, SF-6D yielded higher score, whereas EQ-5D-5 L inclined to produce higher scores for better health status. This is means that these two measures cannot be used interchangeably.

Our convergent validity analysis showed that the ODI was interrelated strongly with the EQ-5D-5 L while moderately with SF-6D. One may find this is in agreement with the previously published research [16]. The EQ-5D-5 L was more correlated with the EQ-VAS than SF-6D. A possible explanation could be that self-rated health on a VAS is a fragment of the EQ-5D-5 L, both measure the health state on the day of interview. However, a four-week recall period is used for SF-6D, which is derived from the SF-36. The fact that the SF-6D was derived from the SF-36 might show positive impact on the correlations among SF-6D and the PCS and MCS. However, the EQ-5D-5 L was more related with PCS, the SF-6D was more correlated with MCS. This is in line with previous studies from Richardson et al. [12] and Sakthong et al. [36]. Due to the fact that four of five items of the EQ-5D-5 L covers physical health, while the SF-6D entails a relatively equivalent number of physical-related items and mental-related items, one may find that the EQ-5D-5 L performs better for individuals with more physical-related health problems than those with mental-related problems $[12,36]$. Given the concern that the items of ODI are more physical-related than psychological-related, this might explain that ODI correlated strongly with the EQ-5D-5 L while only moderately with SF-6D.

Both measures can discriminate patients in most known groups. EQ-5D-5 L provided higher ES and RE values for all known groups apart from location and general health grouped by the general assessment of health item from SF-36. It turned out that the outcomes of validity analysis here were in agreement with previously published studies [14, 36]. EQ-5D-5 L was $42 \%$ more efficient than SF-6D at detecting clinically relevant differences measured by ODI. Furthermore, the AUC score of EQ-5D-5 L was higher, even though there was some overlapping of $95 \%$ confidence interval between these 
Table 5 Efficiency of EQ-5D-5 L and SF-6D to detect differences of dichotomized ODI groups

\begin{tabular}{|c|c|c|c|c|c|c|c|}
\hline \multirow[t]{2}{*}{ Measure } & \multirow{2}{*}{$\begin{array}{l}\text { Dichotomies of ODI } \\
\text { health statust }\end{array}$} & \multirow[t]{2}{*}{ N (\%) } & \multirow[t]{2}{*}{ Mean \pm SD } & \multirow[t]{2}{*}{ ES } & \multirow[t]{2}{*}{ RE } & \multicolumn{2}{|c|}{ ROC curve } \\
\hline & & & & & & AUC & $95 \% \mathrm{Cl}$ \\
\hline \multirow[t]{2}{*}{ EQ-5D-5 L } & 1 & 95 (35\%) & $0.85 \pm 0.13$ & 0.42 & 1.48 & $0.89^{*}$ & $(0.85,0.93)$ \\
\hline & $2-5$ & 177 (65\%) & $0.47 \pm 0.34$ & & & & \\
\hline \multirow[t]{2}{*}{$S F-6 D$} & 1 & 95 (35\%) & $0.7 \pm 0.14$ & 0.28 & 1 & $0.82^{*}$ & $(0.77,0.87)$ \\
\hline & $2-5$ & 177 (65\%) & $0.54 \pm 0.11$ & & & & \\
\hline \multirow[t]{2}{*}{ EQ-5D-5 L } & 1 and 2 & 193 (71\%) & $0.76 \pm 0.18$ & 0.47 & 1.4 & $0.93^{*}$ & $(0.90,0.97)$ \\
\hline & $3-5$ & 79 (29\%) & $0.22 \pm 0.32$ & & & & \\
\hline \multirow[t]{2}{*}{ SF-6D } & 1 and 2 & 193 (71\%) & $0.64 \pm 0.13$ & 0.33 & 1 & $0.87^{*}$ & $(0.82,0.91)$ \\
\hline & $3-5$ & 79 (29\%) & $0.48 \pm 0.1$ & & & & \\
\hline \multirow[t]{2}{*}{ EQ-5D-5 L } & $1-3$ & 240 (88\%) & $0.69 \pm 0.24$ & 0.27 & 1.33 & $0.97^{*}$ & $(0.94,0.99)$ \\
\hline & 4 and 5 & $32(12 \%)$ & $-0.04 \pm 0.25$ & & & & \\
\hline \multirow[t]{2}{*}{$S F-6 D$} & $1-3$ & $240(88 \%)$ & $0.61 \pm 0.14$ & 0.2 & 1 & $0.91^{*}$ & $(0.86,0.95)$ \\
\hline & 4 and 5 & 32 (12\%) & $0.43 \pm 0.07$ & & & & \\
\hline
\end{tabular}

†1 to 5 represents different levels of low back pain measured by ODI from minimal disability to bedbound

*indicates that area under the ROC curve statistically significantly greater than 0.5 and that measure has discriminatory power $(P<0.001)$

EQ-5D-5 L 5-level EuroQol 5-dimension, SF-6D Short Form 6-dimension, ODI Oswestry Disability Index, SD Standard deviations, ES Effect size, RE Relative efficiency, ROC Receiver Operating Characteristic, AUC Area Under Curve, $\mathrm{Cl}$ Confidence Interval

two measures. Our study do not support the findings of Johnsen et al. [16], which concluded that SF-6D had the better ability of detecting clinical change of LBP patients than EQ-5D-3 L. Quite a few studies in various patient populations have found that EQ-5D-5 L is more discriminative than the EQ-5D-3 L [17-22, 57, 58]. Therefore, in all likelihood the increased discriminative power from the 2 additional categories is the reason for the disagreement between our research and previous study [16].

It was hypothesized that patients with higher income should have higher utility scores. Nevertheless, the estimates of utility scores of different income groups showed different results. Specifically, those who earned more than 5000 yuan had lower utility scores than those who had income between 3501 to 5000 yuan. We further analyzed the ODI for different income groups, which indicated similar tendency of health utility score. The survey was conducted at both outpatient clinics and inpatients clinics. With higher possibility to afford the operation, more severe LBP patients with high income were recruited for this research, which may explain above-mentioned issue.

The overall dissimilarity among different measures is the product of the differences in description, valuation and changes in population views of health. Since there is no comparability between the health utility scores measured by different methods [59], a rather consistent measure should be suggested. For example, EQ-5D is the only health utility measure that the National Institute of Health and Care Excellence (NICE) in England recommends. In many respects, EQ-5D-5 L is superior to the $3 \mathrm{~L}$ version including distributional evenness, efficiency of scale use and the face validity of the resulting distributions [60]. In many cases, EQ-5D-5 L performed better than the SF-6D. If SF-6D was used in relative clinical trial, mapping algorithm might be needed.

Obviously, there are a number of limitations to this study. Firstly, responsiveness and reliability of EQ-5D-5 L and SF-6D, which are also essential factors to choose a proper measure, were not evaluated in this study. Secondly, considering the rank of this survey is characteristic, ODI, EQ-5D-5 L and SF-36, questions in ODI may have context effect on EQ-5D-5 L, moreover, questions in ODI and EQ-5D-5 L may have context effect on SF-36. The term "context effect" refers to a process in which prior questions affect responses to later questions in surveys [61]. Thirdly, since there was no Chinese value set for SF-6D, Hong Kong value set was applied, which might influence our findings. Fourth, interview administration rather than self-completed mode of administration was applied in this research, which might influence the generalizability of the outcomes. Finally, the sample were recruited from the orthopedics outpatient and inpatient clinic from one tertiary hospital in China, hence, the conclusion here might be less representative for LBP patients from other locations as well as non-Chinese population.

\section{Conclusion}

The outcomes of this research show that both EQ-5D-5 $\mathrm{L}$ and SF-6D are valid instruments in Chinese low back pain patients, but these two measures cannot generally be used interchangeably. The EQ-5D-5 L was superior to the SF-6D in Chinese low back pain patients attending this hospital, with stronger correlation to ODI, better known-groups validity. Further study needs to evaluate other factors, such as responsiveness and reliability. 


\section{Abbreviations}

AUC: Area under the curve; EQ-5D: EuroQol 5-dimension; EQ-5D-3 L: 3-level version of the EQ-5D; EQ-5D-5 L: 5-level EuroQol 5-dimension; EQVAS: EuroQol visual analog scale; ES: Effect size; HRQL: Health-related quality of life; ICCs: Intra-class correlation coefficients; LBP: Low back pain; MCS: Mental component summary; ODI: Oswestry Disability Index; PCS: Physical component summary; QALYs: Quality-adjusted life years; RE: Relative efficiency; ROC: Receiver operating characteristic; SD: Standard deviations; SF-36: 36-item Short Form Health Survey; SF-6D: Short Form 6-dimension

\section{Acknowledgements}

We are very grateful for the participants in this research.

\section{Funding}

There is no funding for this research.

\section{Availability of data and materials}

Not applicable.

\section{Authors' contributions}

$Z Y$ and LS were responsible for the study design; $Z Y$ and $Q W$ were responsible for patient recruitment and data collection; $Z Y$ was responsible for statistical analysis; ZY and LS were responsible for interpretation of results and final preparation of the manuscript. All authors read and approved the final manuscript.

\section{Ethics approval and consent to participate}

Low back pain patients were recruited at the General Hospital of Shenyang Military Area Command. Informed consent was obtained from each patient. The Ethics Committee of the General Hospital of Shenyang Military Area Command granted ethics approval (Code of Ethics: K (2017)22).

\section{Consent for publication}

Written consent was acquired from each patient.

\section{Competing interests}

The authors declare that they have no competing interests.

\section{Publisher's Note}

Springer Nature remains neutral with regard to jurisdictional claims in published maps and institutional affiliations.

\section{Author details}

'College of Business Administration, Shenyang Pharmaceutical University, Shenyang, China. ${ }^{2}$ Department of orthopedics, The General Hospital of Shenyang Military Area Command, Shenyang, China.

\section{Received: 20 March 2018 Accepted: 2 April 2019}

\section{Published online: 11 April 2019}

\section{References}

1. Taylor-Stokes G, Lobosco S, Pike J, et al. Relationship between patientreported chronic low back pain severity and medication resources. Clin Ther. 2011;33(11):1739-48. https://doi.org/10.1016/j.clinthera.2011.09.026.

2. Jin $L$, Jia M, Xu F. Prevalence of low back pain in Chinese nurses:a metaanalysis. Chin J Pract Nursing. 2013;29(20):45-7. https://doi.org/10.3760/cma. j.issn.1672-7088.2013.20.016.

3. Jin J, Han S, Li K. Epidemiological investigation of back pain and spondyloarthritis in Shougang resident communities. Chin J Intern Med. 2010;49(10):832-5. https://doi.org/10.3760/cma.j.issn.0578-1426.2010.10.006

4. Andersson GB. Epidemiological features of chronic low-back pain. Lancet. 1999;354(9178):581 doi.org/10.1016/50140-6736(99)01312-4.

5. Brazier J, Ratcliffe J, Salomon JA, et al. Measuring and valuing health benefits for economic evaluation. Oup Catalogue. 2007;(1):6-12.

6. Siegel JE, Weinstein MC, Russell LB, et al. Recommendations for reporting cost-effectiveness analyses. Panel on cost-effectiveness in health and medicine. Jama. 1996;276(16):1339.

7. Räsänen $\mathrm{P}$, Roine $\mathrm{E}$, Sintonen $\mathrm{H}$, et al. Use of quality-adjusted life years for the estimation of effectiveness of health care: a systematic literature review. Int J Technol Assess Health Care. 2006;22(2):235-41. https://doi.org/10.1017/ S0266462306051051.
8. Herdman M, Gudex C, Lloyd A, et al. Development and preliminary testing of the new five-level version of EQ-5D (EQ-5D-5L). Qual Life Res. 2011;20(10): 1727-36. https://doi.org/10.1007/s11136-011-9903-X.

9. Luo N, Liu G, Li M, et al. Estimating an EQ-5D-5L value set for China. Value Health. 2017;20(4):662-9. https://doi.org/10.1016/j.jval.2016.11.016.

10. Brazier J, Roberts J, Deverill M. The estimation of a preference-based measure of health from the SF-36. J Health Econ. 2002;21(2):271-92. https:// doi.org/10.1016/S0167-6296(01)00130-8.

11. Mihalopoulos C, Chen G, lezzi A, et al. Assessing outcomes for cost-utility analysis in depression: comparison of five multi-attribute utility instruments with two depression-specific outcome measures. Br J Psychiatry. 2014; 205(5):390-7. https://doi.org/10.1192/bjp.bp.113.136036.

12. Richardson J, lezzi A, Khan MA, et al. Measuring the sensitivity and construct validity of 6 utility instruments in 7 disease areas. Medical Decision Making An Internation. 2015;36(2):147. https://doi.org/10.1177/0272989X15613522.

13. Campbell JA, Palmer AJ, Venn A, et al. A head-to-head comparison of the EQ5D-5L and AQoL-8D multi-attribute utility instruments in patients who have previously undergone bariatric surgery. Patient-patient Centered Outcomes Research. 2016:9(4):311-22. https://doi.org/10.1007/s40271-015-0157-5.

14. Yang F, Lau T, Lee E, et al. Comparison of the preference-based EQ-5D-5L and SF-6D in patients with end-stage renal disease (ESRD). Eur J Health Econ. 2015;16(9):1019-26. https://doi.org/10.1007/s10198-014-0664-7.

15. Søgaard R, Christensen FB, Videbaek TS, et al. Interchangeability of the EQ5D and the SF-6D in long-lasting low Back pain. Value Health. 2009;12(4): 606-12. https://doi.org/10.1111/1.1524-4733.2008.00466.x.

16. Johnsen LG, Christian H, Nygaard ØP, et al. Comparison of the SF6D, the EQ5D, and the oswestry disability index in patients with chronic low back pain and degenerative disc disease. BMC Musculoskelet Disord. 2013;14(1): 148. https://doi.org/10.1186/1471-2474-14-148.

17. Janssen MF, Birnie E, Haagsma JA, et al. Comparing the standard EQ-5D three-level system with a five-level version. Value Health. 2008;11(2):275-84. https://doi.org/10.1111/j.1524-4733.2007.00230.x.

18. Ferreira $L N$, Ferreira $P L$, Ribeiro FP, et al. Comparing the performance of the EQ-5D-3L and the EQ-5D-5L in young Portuguese adults. Health Qual. Life Outcomes. 2016;14(1):1-10. https://doi.org/10.1186/s12955-016-0491-X.

19. Kim TH, Jo MW, Lee SI, et al. Psychometric properties of the EQ-5D-5L in the general population of South Korea. Qual Life Res. 2013;22(8):2245-53. https://doi.org/10.1007/s11136-012-0331-3.

20. Golicki D, Niewada M, Karlińska A, et al. Comparing responsiveness of the EQ-5D-5L, EQ-5D-3L and EQ VAS in stroke patients. Qual Life Res. 2015;24(6): 1555-63. https://doi.org/10.1007/s11136-014-0873-7.

21. Pan $C$, Sun $H$, Wang $X$, et al. The EQ-5D-5L index score is more discriminative than the EQ-5D-3L index score in diabetes patients. Qual Life Res. 2015;24(7):1767. https://doi.org/10.1007/s11136-014-0902-6.

22. Jia $Y X$, Cui FQ, Li L, et al. Comparison between the EQ-5D-5L and the EQ5D-3L in patients with hepatitis B. Qual Life Res Int J Qu. 2014;23(8):235563. https://doi.org/10.1007/s11136-014-0670-3.

23. Walters SJ. Quality of life outcomes in clinical trials and health-care evaluation; 2009.

24. Carreon LY, Bratcher KR, Nienhuis J, et al. Estimating EQ-5D values from the Oswestry disability index and numeric rating scales for back and leg pain. Spine. 2014;39(8):678-82. https://doi.org/10.1016/j.spinee.2013.07.127.

25. Mcghee SM, Brazier J, Lam CLK, et al. Quality-adjusted life years: populationspecific measurement of the quality component. Hong Kong Med J. 2011; 17(Suppl 6(6):17-21.

26. Ferreira $L N$, Ferreira PL, Pereira LN, et al. Exploring the consistency of the SF-6D. Value Health. 2013;16(6):1023-31. https://doi.org/10.1016/j.jval.2013.06.018.

27. Official website of QualityMetric: http://campaign.optum.com/optumoutcomes.html. Accessed 25 Mar 2018.

28. Fairbank JC, Couper J, Davies JB, et al. The Oswestry low back pain disability questionnaire. Physiotherapy. 1980;66(8):271.

29. Irmak R, Baltaci G, Ergun N. Long term test-retest reliability of Oswestry disability index in male office workers. Work. 2016;53(3). https://doi.org/10. 3233/WOR-152234.

30. Yates M, Shastri-Hurst N. The Oswestry disability index. Occup Med. 2017; 67(3):241-2.

31. Zheng G, Zhao X, Liu G, et al. Reliability of the modified Oswestry disability index for evaluating patients with low back pain. Chin J Spine Spinal Cord. 2002;12(1):13-5. https://doi.org/10.3969/j.issn.1004-406X.2002.01.004.

32. George D, Mallery P. IBM SPSS statistics 23 step by step: A simple guide and reference[M]. London: Routledge; 2016. 
33. Bland JM, Altman D. Statistical methods for ASSESSING agreement between two methods of clinical measurement [j]. Lancet. 1986;327(8476):307-10 https://doi.org/10.1016/s0140-6736(86)90837-8.

34. Cicchetti DV. Guidelines, criteria, and rules of thumb for evaluating normed and standardized assessment instruments in psychology. Psychol Assess. 1994;6(4):284-90.

35. Giavarina D. Understanding Bland Altman analysis. Biochemia Medica. 2015; 25(2):141. https://doi.org/10.11613/BM.2015.015.

36. Sakthong P, Munpan WA. Head-to-head comparison of UK SF-6D and Thai and UK EQ-5D-5L value sets in Thai patients with chronic diseases. Applied Health Economics \& Health Policy. 2017;15:1-11. https://doi.org/10.1007/ s40258-017-0320-3.

37. Dritsaki M, Petrou S, Williams M, et al. An empirical evaluation of the SF-12 SF-6D, EQ-5D and Michigan hand outcome questionnaire in patients with rheumatoid arthritis of the hand. Health Qual Life Outcomes. 2017;15(1):20. https://doi.org/10.1186/s12955-016-0584-6.

38. Pickard AS, Wilke $C$, Jung $E$, et al. Use of a preference-based measure of health (EQ-5D) in COPD and asthma. Respir Med. 2008;102(4):519-36. https://doi.org/10.1016/j.rmed.2007.11.016

39. de Vet HCW, Terwee CB, Mokkink LB, et al. Measurement in medicine: a practical guide[M]. London: Cambridge University Press; 2011.

40. Delitto A, George SZ, Dillen LV, et al. Low Back pain: clinical practice guidelines linked to the international classification of functioning, disability, and health from the Orthopaedic section of the American Physical Therapy Association. J Orthop Sports Phys Ther. 2012;42(4):A1. https://doi.org/10. 2519/jospt.2012.42.4.A1.

41. Tincello D, Sculpher M, Tunn R, et al. Patient characteristics impacting health state index scores, measured by the EQ-5D of females with stress urinary incontinence symptoms. Value Health. 2010;13(1):112-8. https://doi. org/10.1111/j.1524-4733.2009.00599.x

42. Sun S, Chen J, Johannesson M, et al. Population health status in China: EQ5D results, by age, sex and socio-economic status, from the National Health Services Survey 2008. Qual Life Res. 2011;20(3):309-20. https://doi.org/10. 1007/s11136-010-9762-x.

43. Sun S, Chen J, Johannesson M, et al. Regional differences in health status in China: population health-related quality of life results from the National Health Services Survey 2008. Health \& Place. 2011;17(2):671-80. https://doi. org/10.1016/j.healthplace.2011.01.007.

44. Sultana M, Sarker A R, Mahumud R A, et al. Inequalities in health status from EQ-5D findings: a cross-sectional study in low-income communities of Bangladesh. Int J Health Policy Manag, 2016(5(x)):301-308. doi: https://doi. org/10.15171/ijhpm.2016.06.

45. Yang M. Income,Income inequality and health status in rural China. Population \& Economics. 2011

46. Barton GR, Sach TH, Avery AJ, et al. A comparison of the performance of the EQ-5D and SF-6D for individuals aged $>0 \mathrm{O}=45$ years. Health Econ. 2008; 17(7):815-32. https://doi.org/10.1002/hec.1298

47. Sheskin D J. Handbook of parametric and nonparametric statistical procedures[M]. Cleveland: CRC Press; 2003

48. Tomczak M, Tomcak E. The need to report effect size estimates revisited. An overview of some recommended measures of effect size. Trends in Sport Sciences. 2014.

49. Drummond $\mathrm{M}$. Introducing economic and quality of life measurements into clinical studies. Ann Med. 2001;33(5):344.

50. Petrou S, Hockley C. An investigation into the empirical validity of the EQ-5D and SF-6D based on hypothetical preferences in a general population. Health Econ. 2005;14(11):1169. https://doi.org/10.1002/hec. 1006.

51. Sayah FA, Qiu W, Xie F, et al. Comparative performance of the EQ-5D-5L and SF-6D index scores in adults with type 2 diabetes. Qual Life Res. 2017; 26(8):2057. https://doi.org/10.1007/s11136-017-1559-8.

52. Montazeri A, Mousavi S J. Quality of Life and Low Back Pain. Handbook of Disease Burdens \& Quality of Life Measures. 2010;3979-3994. doi: https://doi. org/10.1007/978-0-387-78665-0_232

53. Wu J, Han Y, Zhao FL, et al. Validation and comparison of EuroQoL-5 dimension (EQ-5D) and short Form-6 dimension (SF-6D) among stable angina patients. Health \& Quality of Life Outcomes. 2014;12(1):156. https:// doi.org/10.1186/s12955-014-0156-6.

54. Zhao $\mathrm{FL}$, Yue $\mathrm{M}$, Yang $\mathrm{H}$, et al. Validation and comparison of EuroQol and short form 6D in chronic prostatitis patients. Value Health. 2010;13(5):64956. https://doi.org/10.1111/j.1524-4733.2010.00728.x.
55. Brazier J, Roberts J, Tsuchiya A, et al. A comparison of the EQ-5D and SF-6D across seven patient groups. Health Econ. 2004;13(9):873-84. https://doi.org/ 10.1002/hec.866

56. Mcdonough CM, Grove MR, Tosteson TD, et al. Comparison of EQ-5D, HUI, and SF-36-derived societal health state values among spine patient outcomes research trial (SPORT) participants. Qual Life Res. 2005;14(5):132132. https://doi.org/10.1007/s11136-004-5743-2.

57. Agborsangaya CB, Lahtinen M, Cooke T, et al. Comparing the EQ-5D $3 \mathrm{~L}$ and $5 \mathrm{~L}$ : measurement properties and association with chronic conditions and multimorbidity in the general population. Health \& Quality of Life Outcomes. 2014;12(1):74. https://doi.org/10.1186/1477-7525-12-74

58. Janssen MF, Pickard AS, Golicki D, et al. Measurement properties of the EQ5D-5L compared to the EQ-5D-3L across eight patient groups: a multicountry study. Qual Life Res. 2013;22(7):1717-27. https://doi.org/10.1007/ \$11136-012-0322-4.

59. Davidson DT. Levin $L \AA$. Is the societal approach wide enough to include relatives? Appl Health Econ Health Policy. 2010;8(1):25-35. https://doi.org/10. 1007/BF03256163.

60. Janssen MF, Bonsel GJ, Luo N. Is EQ-5D-5L better than EQ-5D-3L? A headto-head comparison of descriptive systems and value sets from seven countries. Pharmacoeconomics. 2018;36(6):675-97. https://doi.org/10.1007/ s40273-018-0623-8.

61. Lavrakas PJ. ENCYCLOPEDIA OF SURVEY RESEARCH METHODS. Bms bulletin of Sociol Methodol. 2008;24(98):83-4.

\section{Ready to submit your research? Choose BMC and benefit from:}

- fast, convenient online submission

- thorough peer review by experienced researchers in your field

- rapid publication on acceptance

- support for research data, including large and complex data types

- gold Open Access which fosters wider collaboration and increased citations

- maximum visibility for your research: over $100 \mathrm{M}$ website views per year

At BMC, research is always in progress.

Learn more biomedcentral.com/submissions 